\title{
PRODUCT MARKET COMPETITION, INVESTMENT AND EMPLOYMENT-ABUNDANT VERSUS JOB-POOR GROWTH: A ReAl Options PeRspective
}

\author{
YU-FU CHEN \\ MICHAEL FUNKE
}

CESIFO WORKING PAPER NO. 1563

CATEgory 5: Fiscal Policy, MACROECONOMICS AND GROWTH

OCTOBER 2005

\footnotetext{
An electronic version of the paper may be downloaded

- from the SSRN website:

www.SSRN.com

- from the CESifo website:

www.CESifo-group.de
} 


\title{
PRODUCT MARKET COMPETITION, INVESTMENT AND EMPLOYMENT-ABUNDANT VERSUS JOB-POOR GROWTH: A REAL OPTIONS PERSPECTIVE
}

\begin{abstract}
The role of product market reforms in achieving the objective of higher employment and growth has recently received much attention amongst academics. The aim of this paper is to analyse some of the channels through which cross-market effects come about and to assess their policy relevance. The analytic strategy of this paper relies upon the stochastic real options modelling approach. In a nutshell, our simulations using numerical methods indicate that comprehensive product market reforms would increase factor demand and growth significantly in the medium and long run.
\end{abstract}

JEL Code: C61, D81, D92, J23, L51.

Keywords: product market competition, regulation, real options, investment, employment.

$\mathrm{Yu}-\mathrm{Fu}$ Chen

Department of Economic Studies

University of Dundee

Dundee DD1 4HN

United Kingdom

y.f.chen@dundee.ac.uk
Michael Funke

Department of Economics

Hamburg University

Von-Melle-Park 5

20146 Hamburg

Germany

funke@econ.uni-hamburg.de 


\section{Introduction}

This paper contributes to the growing literature which aims to link barriers to competition on product markets and factor demand. The recent decline in economic growth in some European countries has intensified the debate surrounding the question of the extent to which the inertia of highly regulated labour and product markets has a negative impact on the creation of jobs and unemployment. Since the timing of UK and US product market deregulation, which began in the late 1970s, fits neatly into the picture of diverging labour market performance dating back to the 1980 s, the regulatory product market environment is a smoking gun of sorts for divergent labour market performances across countries [see, e.g., Blanchard and Tirole (2004) and Nickell et al. (2005)].

In recent years the OECD has produced an internationally-comparable set of indicators that measure the degree to which policies promote or inhibit employment and competition in various areas of the product market. ${ }^{1}$ A broad range of policies and institutional arrangements have influenced these differences. Using a multidimensional clustering approach, Boeri et al. (2000) have grouped the OECD countries into various clusters of institutional rigidities according to the degree of labour and product market regulation. They have identified four groups: (a) countries which combine tight regulation in both labour and product markets (France, Italy, Greece and Spain); (b) continental European countries with relatively restrictive product market regulation but with different employment protection legislation (Germany, Austria, the Netherlands, Finland and Portugal being more restrictive than Belgium and Denmark); (c) common law countries characterised by a relatively liberal approach in both labour and product markets (US, UK, Canada, Ireland, Australia and New Zealand), and (d) Sweden, which together with Japan, combines relatively restrictive labour market regulation with relatively few product market restrictions. ${ }^{2}$

All this is by way of prologue. A proper discussion of the effects that changing product market competition brings to the rest of the economy demands that policy oriented debate is placed within the context of economic theory. ${ }^{3}$ Once one moves away from the idea of a simple world where firms have perfect foresight, additional linkages and further questions suggest themselves. In particular, in an

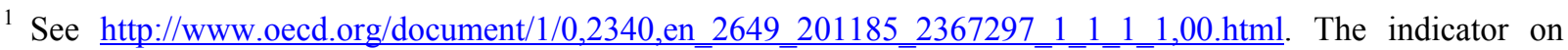
product market regulation focuses on a subset of government-imposed restrictions. These include state control, barriers to entrepreneurship, barriers to trade and investment, and economic and administrative regulation. The indicator on employment protection summarises regulation for regular and temporary contracts. The 'Doing Business Database' of the Worldbank also provides alternative measures of business regulations and their enforcement in international comparison. This dataset covers 145 countries and is benchmarked to January 2004 (see, http://rru.worldbank.org/DoingBusiness/).

${ }^{2}$ A number of insightful empirical studies have analysed the linkages between product market regulations and employment using these cardinal indicators, including Alesina et al. (2005), Angrist and Kugler (2003), Hayri and Dutz (1999), IMF (2005) and Koedijk and Kremers (1996). These studies, however, suffer from two problems. First, most studies use country data, which "aggregates out" the true dynamics of factor demand. Second, either employment or investment is investigated instead of modelling them jointly.

${ }^{3}$ Bayoumi et al. (2004), for example, have tackled the impact of regulation on the aggregate growth and welfare in a general-equilibrium simulation model with nominal rigidities and monopolistic competition in product and
} 
uncertain environment barriers to competition may affect not only the level of investment/hiring but also the timing of investment/hiring. Hence we contribute to the literature by taking the route of a real options modelling framework to shed more light on the regulation - factor demand nexus. ${ }^{4}$

Against this background, the remainder of the paper is structured as follows: Section 2 sets out the theoretical model. Section 3 focuses on our main research question - posed in the title of the paper namely, how much of the labour-abundant versus job-poor growth experiences can barriers to competition explain? Finally, based on our results, some concluding remarks are offered in section 4 .

\section{A Real Options Model of (Partially) Irreversible Interrelated Factor Demand Decisions}

Recent theoretical analyses of factor demand under uncertainty have highlighted the effects of irreversibility in generating "real options". In these models the interaction of time-varying uncertainty and irreversibility leads to a range of inaction where factor demand is zero as the firm prefers to "wait and see" rather than undertaking a costly action with uncertain consequences. Indeed, waiting allows firms to gather new information on the uncertain future. Bowman and Maskowitz (2001, p. 777) have recently concluded that the real options approach "encourages experimentation and the proactive exploration of uncertainty" and thus a "revolution in thinking". Below we therefore develop a real options model with two types of inputs (capital and labour) and a rich specification of adjustment costs. Given the model, we can characterise specific channels through which the impact of product market regulation unfolds.

\subsection{Analytical Framework}

We now describe the partial equilibrium modelling framework in detail. To keep the analysis simple, we consider a representative firm facing the following Cobb-Douglas production function

$$
Y_{t}=a K_{t}^{\alpha} L_{t}^{1-\alpha}, 0<\alpha<1
$$

where $Y_{t}$ denotes real output, $L_{t}$ is the total number of employees, $K_{t}$ is the capital stock, $\alpha$ is the distribution parameters between $K_{t}$ and $L_{t}$, and $a$ denotes a positive parameter measuring the

labor markets. They find that greater competition produces large effects on macroeconomic performance, as measured by standard indicators.

${ }^{4}$ The analogy arises because factor adjustment costs are at least partially sunk. The consequences of uncertainty for the optimal conduct of factor demand have been a very active field of research in recent years. Amran and Kulatilaka (1999), Copeland and Antikarov (2001), Coy (1999) and Dixit and Pindyck (1994) summarise the principle features of this class of model. 
productivity of available technology. ${ }^{5} K_{t}$ is subject to changes due to depreciation of capital stocks and the optimal (dis-)investment decisions by the firm over time. Similarly, $L_{t}$ is subject to changes due to quits and/or the optimal employment (hiring and firing) decisions by the firm. We allow for imperfect competition, i.e. we assume that the firm faces an isoelastic demand function

$$
p=Y_{t}^{(1-\psi) / \psi} Z_{t}, \quad \psi \geq 1
$$

where $p$ represents the real price, $Z_{t}$ denotes a random variable describing demand shocks, and $\psi$ is an elasticity parameter that takes its minimum value of 1 under perfect competition [see, Abel and Eberly (1994)]. This leads to a definition of the elasticity of demand as:

$$
\eta_{D}=-\frac{p}{Y p^{\prime}}=-\frac{Y^{(1-\psi) / \psi} Z}{\frac{1-\psi}{\psi} Y^{(1-\psi) / \psi} Z}=-\frac{\psi}{1-\psi} .
$$

Thus, equation (2) can also be written as:

$$
p=f=Y_{t}^{-\frac{1}{\eta_{D}}} Z_{t}
$$

The current profits stream, measured in units of output, is defined as:

$$
\Pi=a^{\frac{1}{\psi}} Z_{t} K_{t}^{\frac{\alpha}{\psi}} \frac{1-\alpha}{L_{t}{ }^{\frac{1-\alpha}{2}}}-C\left(I_{t}\right)-H\left(M_{t}\right)-x K_{t}-w L_{t}
$$

where $I_{t}$ denotes gross physical (dis-)investment, $M_{t}$ represents gross changes in employment due to hiring and firing, and quits from employees, $w$ is the constant real wage, and $x$ represents constant service expenses. The costs of adjusting $K_{t}$ and $L_{t}$ are captured by the functions $C\left(I_{t}\right)$ and $H\left(M_{t}\right)$, respectively. Note that the adjustments of $K_{t}$ and $L_{t}$ are governed by the following equations, respectively:

$$
\frac{d K_{t}}{d t}=I_{t}-\delta K_{t}
$$

\footnotetext{
${ }^{5}$ This assumption is made for expositional convenience and plays no crucial role for the qualitative results
} 


$$
\frac{d L_{t}}{d t}=M_{t}-\lambda L_{t}
$$

where $\delta$ is the constant depreciation rate of physical capital and $\lambda$ is the exogenous quit rate of employment. It is assumed that the demand factor $Z$ follows a geometric Brownian motion

$$
d Z_{t}=\eta Z_{t} d t+\sigma Z_{t} d W_{t}
$$

where $W_{t}$ is a Wiener process, $d W_{t}=\varepsilon_{t} \sqrt{d t}$ (since $\varepsilon_{t}$ is a normally distributed random variable with mean zero and a standard deviation of unity), $\eta$ is the drift term and $\sigma$ is the variance parameter. ${ }^{6}$ Thus, we have an optimal stopping problem - the firm must determine when it is optimal to purchase/sell physical capital and/or hire/fire workers, given the stochastic evolution of $Z$.

To keep the model simple we abstract from taxes. The representative risk-neutral firm maximises its discounted flow of profits. ${ }^{7}$ The firm's factor demand decisions are the outcome of the following intertemporal profit maximisation

$$
V=\max _{I_{t}, M_{t}} E_{t}\left[\int_{0}^{\infty}\left(a^{\frac{1}{\psi}} Z_{t} K_{t}^{\frac{\alpha}{\psi}} \frac{1-\alpha}{L_{t}^{\psi}}-C\left(I_{t}\right)-H\left(M_{t}\right)-x K_{t}-w L_{t}\right) e^{-r s} d s \mid Z_{0}=Z, K_{0}=K, L_{0}=L\right],
$$

where $r$ is the constant real interest rate and $E_{t}[\cdot]$ denotes the mathematical expectation given the information set available to the firm. The following assumptions of adjustment costs guarantee that the firm's problem is well-behaved. ${ }^{8}$ The total costs of physical investment and employment adjustment are determined by:

presented below. The impact of a $C E S$ production function is covered in Chen and Funke (2004), for example.

${ }^{6}$ A standard assumption in the real options literature is that investment does not resolve uncertainty; it is time that resolves uncertainty. Clearly, this exogeneity assumption will not be valid for certain factor demand decisions in which the firm gains the critical information due to the fact that it has invested. For example, R\&D related employment and investment decisions will give the firm information about the likelihood of a product's success. Models of information acquisition in which the stochastic environment is not given but can be influenced have been developed by Cukierman (1980) and Demers (1991). Cukierman (1980) demonstrates a model in which a firm decides which of a range of investment projects to undertake, and "buys" information by waiting, reducing the probability of losses from launching an unsuccessful product. Demers (1991) has a model of a firm which is uncertain about the demand in a particular market, and updates its beliefs according to a Bayesian rule after receiving information through signals.

${ }^{7}$ Hence, we abstract from additional dimensions of employment protection which arise when agents are risk averse. In this case employment protection can serve as a substitute for insurance in incomplete markets.

${ }^{8}$ We therefore depart from the standard assumption that capital (labour) is quasi-fixed while labour (capital) can be adjusted without cost. The idea to examine employment and investment decisions simultaneously using a real options modelling framework is not new. It can be traced back to Eberly and van Mieghem (1997). The analysis accomplished by these authors, however, has not addressed the impact of barriers to competition upon factor demand. 


$$
\begin{array}{r}
C(I)= \begin{cases}p_{K}^{+} I_{t}+\gamma I_{t}^{2} / 2 & \text { for } I_{t}>0 \\
0 & \text { for } I_{t}=0 \\
p_{K}^{-} I_{t}+\gamma I_{t}^{2} / 2 & \text { for } I_{t}<0\end{cases} \\
H(M)= \begin{cases}p_{L}^{+} M_{t}+\mu M_{t}^{2} / 2 & \text { for } M_{t}>0 \\
0 & \text { for } M_{t}=0 \\
-p_{L}^{-} M_{t}+\mu M_{t}^{2} / 2 & \text { for } M_{t}<0 .\end{cases}
\end{array}
$$

Equations (10) and (11) have some distinguishing features that warrant discussion. With no (dis-) investment of $K$ and $L$, the firm can avoid these fixed costs. Purchase (sale) costs are the costs of buying (selling) or hiring (firing) capital. Let $p_{K}^{+}\left(p_{K}^{-}\right)$be the lump-sum price per unit of investment good at which the firm can buy (sell) any amount of capital. Similarly, $p_{L}^{+}\left(p_{L}^{-}\right)$be the sunk costs when the firm paying for hiring (firing) a marginal employee. Note that the firm can sell the redundant physical capital for a positive price. However, if the firm tries to get rid of redundant workers, it needs to pay the firing costs. ${ }^{9}$ We assume that $p_{K}^{+} \geq p_{K}^{-} \geq 0$ and $p_{L}^{+} \geq 0 \geq-p_{L}^{-} \cdot{ }^{10}$ Adjustment costs of $C(I)$ and $H(M)$ are continuous and strictly convex in $I$ and $M$ so as to satisfy and $C_{I I}, H_{M M}>0$ with the positive parameters of $\gamma$ and $\mu .^{11}$

The optimisation problem of the firm is represented by the following Bellman equation via Ito's Lemma:

$$
\begin{aligned}
& r V=\max _{I, M}\left\{a^{\frac{1}{\psi}} Z K^{\frac{\alpha}{\psi}} L^{\frac{1-\alpha}{\psi}}-\left(p_{K}^{+/-} I+\frac{\gamma I^{2}}{2}\right)-\left( \pm p_{L}^{+/-} M+\frac{\mu M^{2}}{2}\right)\right. \\
& \left.-x K-w L+V_{K}(I-\delta K)+V_{L}(M-\lambda L)+\eta Z V_{Z}+\frac{1}{2} \sigma^{2} Z^{2} V_{Z Z}\right\} .
\end{aligned}
$$

The first five terms on the right-hand sides represent the current profit and the sixth and seventh terms denote the changes of $V$ due to depreciation and quits in $K$ and $L$ respectively. The last two terms indicate the impact of demand fluctuations.

\footnotetext{
${ }^{9}$ Chen and Funke (2004) have generalised the standard model of irreversible factor demand by introducing a second fully reversible technology which produces the same output, but at a higher marginal cost. They examine the trade-off between the adjustment of the labour force and hours of work. In their model, firms can optimise on two margins and therefore variations in hours worked serve as a substitute for variations in the numbers of employees.

${ }^{10}$ We are not assuming symmetric adjustment costs due to the fact that they are at odds with the data. The rejection is stronger as the level of data disaggregation rises (e.g. from industry to firm). Using Dutch data, Pfann and Verspagen (1989), for example, obtain evidence in favour of asymmetric adjustment costs.

${ }^{11}$ In practice, hiring costs associated with successfully filling a vacancy will consist of search costs and human capital investment in the worker. Firing costs consist of all costs that are related to a dismissal, especially compensation and costs of legal disputes.
} 


\subsection{First-Order Conditions for $I$ and $M$}

The standard result of real options theory is the prediction of optimal decision rules when to hire (invest) or fire (dis-invest). The rules are usually specified in terms of critical thresholds, or trigger values, describing the exercise region of the involved options. The width of the corridor between these trigger values is a measure of the inertia in factor markets. Under the assumptions sketched out above, the optimal condition for $I$ becomes

$$
p_{K}^{+/-}+\gamma I=q \Rightarrow I=\frac{q-p_{K}^{+/-}}{\gamma},
$$

where $q=V_{K}$. Substituting (13) into (11) and rearranging yields

$$
\begin{aligned}
r V=a^{\frac{1}{\psi}} Z K^{\frac{\alpha}{\psi}} L^{\frac{1-\alpha}{\psi}}+\frac{\left(q-p_{K}^{+/-}\right)^{2}}{2 \gamma}-\left( \pm p_{L}^{+/-} M+\frac{\mu M^{2}}{2}\right) \\
\quad-w L-x K-\delta q K+V_{L}(M-\lambda L)+\eta Z V_{Z}+\frac{\sigma^{2}}{2} Z^{2} V_{Z Z} .
\end{aligned}
$$

The first-order condition for physical investment shows that the optimal investment strategy is a twotrigger policy that can be expressed in terms of Tobin's $q$. If $q$ exceeds the upper threshold value $p_{K}^{+}$ gross physical investment occurs. In turn, if $q$ falls below a lower threshold value $p_{K}^{-}$, negative investment takes place - the firm sells part of its capital stock. In the intermediate region of inaction $p_{K}^{-} \leq q \leq p_{K}^{+}$, investment will be zero. The case of total reversible physical capital investment refers to the condition $p_{K}^{-}=p_{K}^{+}$.

Using the definitions $q=V_{K}, q_{Z}=V_{K Z}, q_{K}=V_{K K}$ and $q_{Z Z}=V_{K Z Z}$ and differentiating both sides of equation (14) with respect to $K$, we have

$$
\begin{aligned}
(r+\delta) q= & \frac{\alpha}{\psi} a^{\frac{1}{\psi}} Z K^{\frac{\alpha}{\psi}-1} L^{\frac{1-\alpha}{\psi}}-x+\frac{\left(q-p_{K}^{+/-}\right) q_{K}}{\gamma} \\
& -\delta q_{K} K+q_{L}(M-\lambda L)+\eta Z q_{Z Z}+\frac{\sigma^{2}}{2} Z^{2} q_{Z Z}
\end{aligned}
$$

It is straightforward to verify that the optimal condition for $M$ is 


$$
\pm p_{L}^{+/-}+\mu M=v \Rightarrow M=\frac{v \pm p_{L}^{+/-}}{\mu}
$$

where $v=V_{L}$ denoting the marginal product of labour. Substituting (16) into (12) and rearranging yields

$$
\begin{aligned}
r V=a^{\frac{1}{\psi}} Z K^{\frac{\alpha}{\psi}} L^{\frac{1-\alpha}{\psi}}-\left( \pm p_{K}^{+/-} I+\frac{\gamma I^{2}}{2}\right)+\frac{\left(v \pm p_{L}^{+/-}\right)^{2}}{2 \mu} \\
\quad-w L-x K+V_{K}(I-\delta K)-\lambda v L+\eta Z V_{Z}+\frac{\sigma^{2}}{2} Z^{2} V_{Z Z} .
\end{aligned}
$$

The first-order condition (17) shows that the optimal strategy is again a two-trigger policy that can be expressed in terms of the marginal product of labour, $v$. If $v$ exceeds the upper threshold value $p_{L}^{+}$; the price of hiring a marginal employee; an additional worker will be hired. In turn, if $v$ falls below a lower threshold value $-p_{L}^{-}$, the firm will fire a marginal employee by paying firing cost $p_{L}^{-}$. In the region of inaction $-p_{L}^{-} \leq v \leq p_{L}^{+}$, the firm will neither hire nor fire. The case of total reversible employment decisions refers to the condition $p_{L}^{-}=p_{L}^{+}=0$, while the case $p_{K}^{-}=0$ implies that capital is fully sunk. Differentiating both sides of equation (17) with respect to $L$, we have

$$
\begin{aligned}
(r+\lambda) v & =\frac{(1-\alpha)}{\psi} a^{\frac{1}{\psi}} Z K^{\frac{\alpha}{\psi}} L^{\frac{1-\alpha}{\psi}-1}-w \\
& +\frac{\left(v \pm p_{L}^{+/-}\right) v_{L}}{\mu}+v_{K}(I-\delta K)-\lambda v_{L} L+\eta Z v_{Z}+\frac{\sigma^{2}}{2} v^{2} v_{Z Z}
\end{aligned}
$$

Equations (14) - (18) are important for understanding the interaction between product market regulation and factor demand. Product market deregulation increases the competitive pressures among firms (lowers $\psi$ ), which lowers the markup. Thus for given wages $w=\bar{w}$ and service expenses $x=\bar{x}$, factor demand increase at the firm level. If the number of firms remains constant, this leads to higher employment because aggregate labour demand increases. ${ }^{12}$

\footnotetext{
${ }^{12}$ If product market deregulation also lowers entry costs, new entry further increases employment. A more competitive institutional setting will thus contribute to a more innovative and dynamic economy through thriving entrepreneurial activity (Acemoglu et al., 2002).
} 


\subsection{The Optimal Stopping Problem for Capital and Labour}

Solving the optimal stopping problem requires a certain amount of finesse. ${ }^{13} \mathrm{We}$ first simplify the problem by observing that we have $q=p_{K}^{+}$and $q=p_{K}^{-}$and $v=p_{L}^{+}$and $v=p_{L}^{-}$within the inaction regions for physical investment and employment decisions ( $I$ and $M$ are zero). Alternatively, we can consider the cases of immediate adjustments of $K$ and $L$ ( $\gamma$ and $\mu$ in (10) and (11) are set to zero). The non-homogenous terms in equations (15) and (18) then disappear accordingly. This implies that equations (15) and (18) can be written as follows:

$$
\begin{aligned}
& (r+\delta) q=\frac{\alpha}{\psi} a^{\frac{1}{\psi}} Z K^{\frac{\alpha}{\psi}-1} L^{\frac{1-\alpha}{\psi}}-x-\delta q_{K} K-\lambda q_{L} L+\eta Z q_{Z}+\frac{\sigma^{2}}{2} Z^{2} q_{Z Z}, \\
& (r+\lambda) v=\frac{(1-\alpha)}{\psi} a^{\frac{1}{\psi}} Z K^{\frac{\alpha}{\psi}} L^{\frac{1-\alpha}{\psi}-1}-w-\delta v_{K} K-\lambda v_{L} L+\eta Z v_{Z}+\frac{\sigma^{2}}{2} v^{2} V_{Z Z} .
\end{aligned}
$$

The solutions for (19) and (20) consist of the particular and general solutions, i.e. $q=q^{P}+q^{G}=p_{K}^{+/-}$ and $v=v^{P}+v^{G}=p_{L}^{+}$or $-p_{L}^{-}$. Given the above model, we can show that the following holds: ${ }^{14}$

$$
\begin{gathered}
q^{P}=\frac{\frac{\alpha}{\psi} a^{\frac{1}{\psi}} Z K^{\frac{\alpha}{\psi}-1} L^{\frac{1-\alpha}{\psi}}}{r+\left(\frac{\alpha}{\psi}\right) \delta+\left(\frac{1-\alpha}{\psi}\right) \lambda-\eta}-\frac{x}{r+\delta}, \\
q^{G}=-A_{1}\left(Z K^{\frac{\alpha}{\psi}-1} L^{\frac{1-\alpha}{\psi}}\right)^{\beta_{1}}+A_{2}\left(Z K^{\frac{\alpha}{\psi}-1} L^{\frac{1-\alpha}{\psi}}\right)^{\beta_{2}},
\end{gathered}
$$

where $\beta_{1}$ and $\beta_{2}$ are the positive and negative roots respectively of the following characteristic equation:

$$
\frac{1}{2} \sigma^{2} \beta(\beta-1)-\delta \beta\left(\frac{\alpha}{\psi}-1\right)-\lambda \beta\left(\frac{1-\alpha}{\psi}\right)+\eta \beta-(r+\delta)=0
$$

\footnotetext{
${ }^{13}$ A mathematically rigorous analysis for models with a discrete set of states is given in Brekke and Øksendal (1994).

${ }^{14}$ The derivations of equations (21) - (26) require a degree of finesse. See Appendices A - D for details. In spirit, equations (21) - (22) are similar to Bertola and Caballero (1994), while equations (24) - (25) are similar to Bentolila and Bertola (1990).
} 
and

$$
\begin{gathered}
v^{P}=\frac{\frac{(1-\alpha)}{\psi} a^{\frac{1}{\psi}} Z K^{\frac{\alpha}{\psi}} L^{\frac{1-\alpha}{\psi}-1}}{r+\left(\frac{\alpha}{\psi}\right) \delta+\left(\frac{1-\alpha}{\psi}\right) \lambda-\eta}-\frac{w}{r}, \\
v^{G}=-A_{3}\left(Z K^{\frac{\alpha}{\psi}} L^{\frac{1-\alpha}{\psi}-1}\right)^{\beta_{3}}+A_{4}\left(Z K^{\frac{\alpha}{\psi}} L^{\frac{1-\alpha}{\psi}-1}\right)^{\beta_{4}},
\end{gathered}
$$

where $\beta_{3}$ and $\beta_{4}$ are the positive and negative roots separately of the following characteristic equation:

$$
\frac{1}{2} \sigma^{2} \beta(\beta-1)-\delta \beta\left(\frac{\alpha}{\psi}\right)-\lambda \beta\left(\frac{1-\alpha}{\psi}-1\right)+\eta \beta-(r+\lambda)=0,
$$

where $A_{1}, A_{1}$ and $A_{3}$ and $A_{4}$ are unknown parameters to be determined by the optimal stopping boundary conditions. The set of boundary conditions that applies to this optimal stopping problem are composed by the value-matching and smooth-pasting conditions. As long as the marginal revenue products lie inside these thresholds, the firm chooses to wait and do nothing.

Let's now define the investment and disinvestment thresholds for capitals by $Z_{K+}$ and $Z_{K-}$, and the hiring and firing thresholds for labour by $Z_{L_{+}}$and $Z_{L_{-}}$. It is then easy to see that the inaction region of physical capital investment is denoted by $Z_{K-}<Z<Z_{K+}$, and the inaction region of employment decisions by $Z_{L_{-}}<Z<Z_{L_{+}}$. Formally, the physical investment thresholds satisfy the following valuematching and smooth-pasting conditions: $:^{15}$

$$
\begin{aligned}
& q^{P}\left(Z_{K_{+}}\right)+q^{G}\left(Z_{K+}\right)=p_{K}^{+}, \\
& q^{P}\left(Z_{K^{-}}\right)+q^{G}\left(Z_{K_{-}}\right)=p_{K}^{-}, \\
& q^{P^{\prime}}\left(Z_{K_{+}}\right)+q^{G}\left(Z_{K_{+}}\right)=0, \\
& q^{P}\left(Z_{K_{-}}\right)+q^{G^{\prime}}\left(Z_{K_{-}}\right)=0 .
\end{aligned}
$$

\footnotetext{
${ }^{15}$ The systems are, in principles, similar to the works by Bentolila and Bertola (1990) for solving employment decisions and by Abel and Eberly (1994) and Bertola and Caballero (1994) for solving the capital investment and employment decisions.
} 
Optimal employment decision-making implies that the hiring/firing thresholds satisfy the valuematching and smooth-pasting conditions

$$
\begin{aligned}
& v^{P}\left(Z_{L+}\right)+v^{G}\left(Z_{L+}\right)=p_{L}^{+}, \\
& v^{P}\left(Z_{L-}\right)+v^{G}\left(Z_{L-}\right)=-p_{L}^{-}, \\
& v^{P^{\prime}}\left(Z_{K+}\right)+v^{G}\left(Z_{K+}\right)=0, \\
& v^{P^{\prime}}\left(Z_{L-}\right)+v^{G}\left(Z_{L-}\right)=0 .
\end{aligned}
$$

In short, the firm solves the somewhat daunting system of equations given by (27) - (34) given the initial values of $K$ and $L$ to obtain the threshold for purchasing physical capital, $Z_{K+}$, the threshold for selling physical capital, $Z_{K-}$, the threshold for hiring a marginal worker, $Z_{L+}$, and the threshold for firing a marginal employee, $Z_{L_{-}}$. Note that it is reasonable to expect the thresholds for $Z_{K+}$ and $Z_{L+}$ a to be different since the sunk costs are different, and the $q$ and $v$ equations are different for given levels of $K$ and $L$. Over time, the thresholds for $Z_{K+}$ and $Z_{L+}$ should change since there exist fixed depreciation rate for physical capital and exogenous quit rate for workers. The same discussions are also applied to the thresholds for $Z_{K-}$ and $Z_{L_{-}}$. We are now in a position to calibrate our model and approach our quantitative questions.

\section{Numerical Simulations}

The complexity of the model necessitates numerical simulation because closed-form solutions cannot be derived. We therefore use numerical simulations to gain further insight into the results of the previous section, to have a "feel" for the model and to "draw a map" of the factor demand sensitivity to various structural characteristics of the environment in which firms operate. We hope to show that the insights gained from simulations are sufficiently rich to indicate that it provides a useful complement to theory.

First we describe the data and parameter assumptions that will be required to calibrate the model. The unit time length corresponds to one year and annual rates are used when applicable. Where possible, parameter values are drawn from empirical studies. Our base parameters which were chosen for realism are $\sigma=0.1, \eta=0.0, r=0.05, \delta=0.05, \lambda=0.08, \psi=1.5, \alpha=0.7, w=1.0, a=14.5, p_{K}^{+}=12.0$, $p_{K}^{-}=6.0\left(50 \%\right.$ of $\left.p_{K}^{+}\right), p_{L}^{+}=0.1, p_{L}^{-}=0.6$ and $x=1.2\left(10 \%\right.$ of $\left.p_{K}^{+}\right)$. For simplicity, we normalise capital and labour such that $K=L=2.0 .^{16}$ The firing and hiring parameters are consistent with those in

\footnotetext{
${ }^{16}$ The calibrated model is not based on detailed time series data in the way econometric models are and does not have the predictive power of the latter. Note, however, that the goal of this paper is not to derive precise
} 
Bentolila and Bertola (1990) for Germany. Their estimated firing costs for Germany are in the range $0.562 \leq p_{L}^{-} \leq 0.750$ and their hiring cost estimate (excluding on-the-job-training) for Germany is 0.066 of the average annual wage. Our specification $\left(p_{L}^{+}=0.1\right)$ is also broadly consistent with the recruiting and training cost of two months in Mortenson and Pissarides' (1999) calibration. They suggest that this number is consistent with survey results reported in Hamermesh (1993). The price elasticity of demand parameter is set at $\Psi=1.50$ as in Bovenberg et al. (1998). Ramey and Shapiro (2001) suggest that $p_{K}^{-}=0.5 p_{K}^{+}$is quite realistic. In practice, measuring product market competition is a complex task. Given that product market competition cannot be measured directly, we need to use proxies. Following Blanchard and Giavazzi (2003), we think of the regulatory stance on the product markets as being captured, admittedly in abstract fashion, by the degree of product market competition, $\psi$. This conveys the message in as simple a manner as possible.

Results for various parameters are displayed in Figures 1 to 7 below. The threshold plots contain four lines plotted in the $(K, L)$ space for values for the firing and hiring thresholds (top and bottom boundaries) and the buy and sell capital thresholds (left and right boundaries). The four boundaries partition the state space into various domains. The (non-empty) interior region of the quadrangle is the region of inaction where $I=M=0$ while outside the quadrangle firing vs. hiring and selling vs. buying will take place according to the optimal values of $I$ and $M$. Eberly and van Mieghem (1997) have shown that the boundaries of the quadrangle are upward-sloping in the usual case of supermodularity (the production function $F(K, L)$ has the property $F_{K L}>0$ and $\left.F_{L K}>0\right)$. Furthermore, they have shown that the boundaries separating different kinds of employment policies are everywhere flatter than the $45^{\circ}$ line, and those for physical capital are steeper than this line in the supermodularity case. As the marginal revenue products evolve stochastically over time, the model predicts that the firm will undertake sporadic bursts of investment/hiring or disinvestment/firing. Which factor of production (capital or labour) is more flexible depends upon whether the investment and disinvestment thresholds are farther apart horizontally than the hiring and firing thresholds are apart vertically. Next we investigate various comparative statics of the quadrangle of inaction. ${ }^{17}$

First, we consider the employment and investment thresholds for alternative hiring and firing costs for a given degree of product market competition, $\psi$. The numerical results are given in Figure 1. The left diagram can be labelled the "no labour market reform" scenario, the right diagram the "labour market reform" scenario.

quantitative estimates of the impact of various labour market regulations, but rather to illustrate the qualitative predictions of the model, and to see what we can learn from this model.

${ }^{17}$ The numerical boundary value problems are solved with the method of Newton-Raphson for nonlinear systems. For a description of the algorithm used to compute the numerical simulations, see Press et al. (2002). 
Figure 1: The Two-Dimensional Quadrangle for $\psi=1.5$ and Different Values of $p_{K}^{-}$and $p_{L}^{-}$
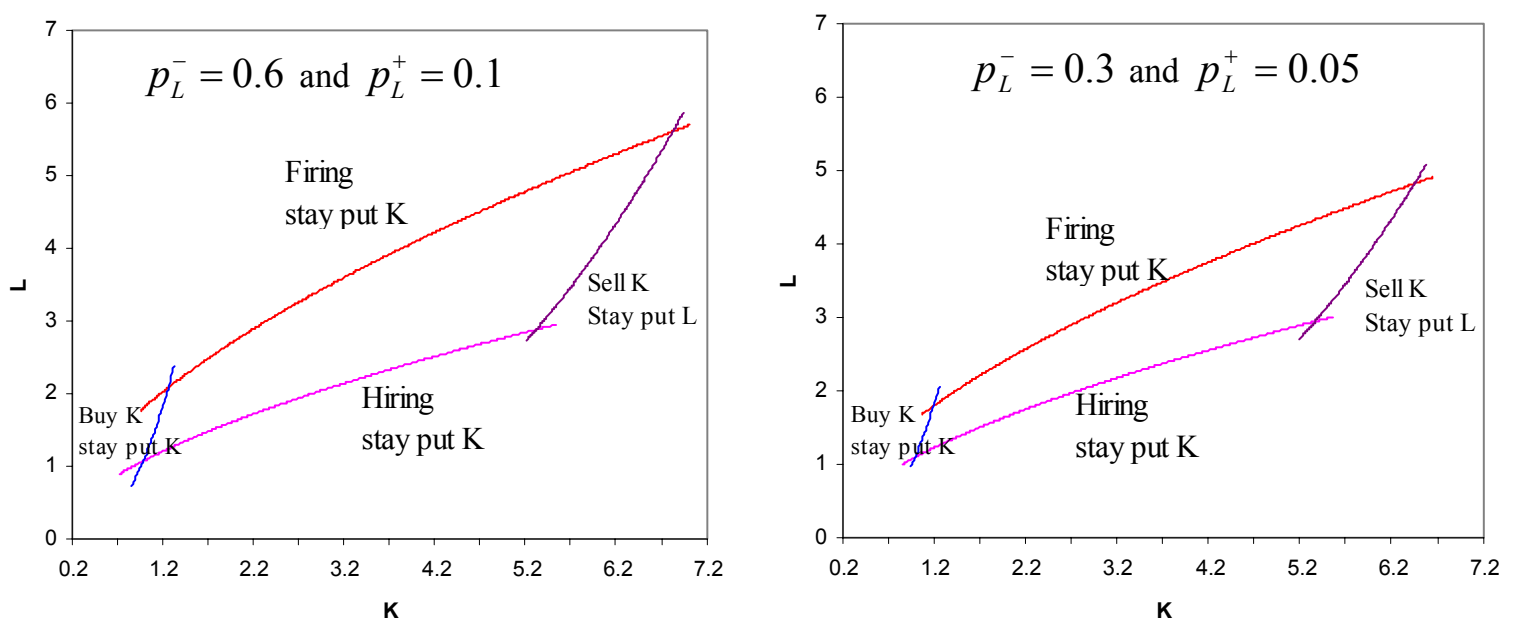

Note: The level of $Z$ is set to 1 in the numerical exercise.

As expected, the major result of the calibrations is that lower hiring and firing costs $\left(p_{L}^{+}=0.05\right.$ and $p_{L}^{-}=0.3$ ) lead to a smaller inaction area for otherwise identical parameters. Decreasing firing costs reduce the (upper) firing employment threshold and therefore more workers would become unemployed in a cyclical downturn because it is easier for firms to fire workers. On the other hand, the (lower) hiring employment threshold is only marginally affected. In common with other studies, our results thus indicate that lowering hiring and firing costs by itself has an asymmetric impact on the employment thresholds, i.e. the policy change encourages firing by more than it does hiring. Therefore, adjustment costs do not necessarily imply a higher equilibrium rate of unemployment in this "shock-based" framework and the overall employment impact of lower firing costs in real options framework may even be negative. ${ }^{18}$ Conversely, one has to admit that heavier adjustment costs lead to microeconomic inflexibility [see, Caballero et al. (2004)]. This tends to hamper the Schumpeterian process of creative destruction at the core of the growth engine in market economies. ${ }^{19}$

\footnotetext{
${ }^{18}$ These simulation results are consistent with previous theoretical and mixed empirical evidence on the impact of labour market regulations. See, e.g., Bentolila and Bertola (1990) and Nickell and Layard (1999).

${ }^{19}$ There is ample evidence that the shift of resources away from less productive and towards more efficient firms accounts for much of the growth in total factor productivity. High adjustment costs may disrupt this process of resource re-allocation [Caballero and Hammour $(1996,1998)]$.
} 
Figure 2: The Two-Dimensional Quadrangle for $\psi=1.6$ and Different Values of $p_{K}^{-}$and $p_{L}^{-}$
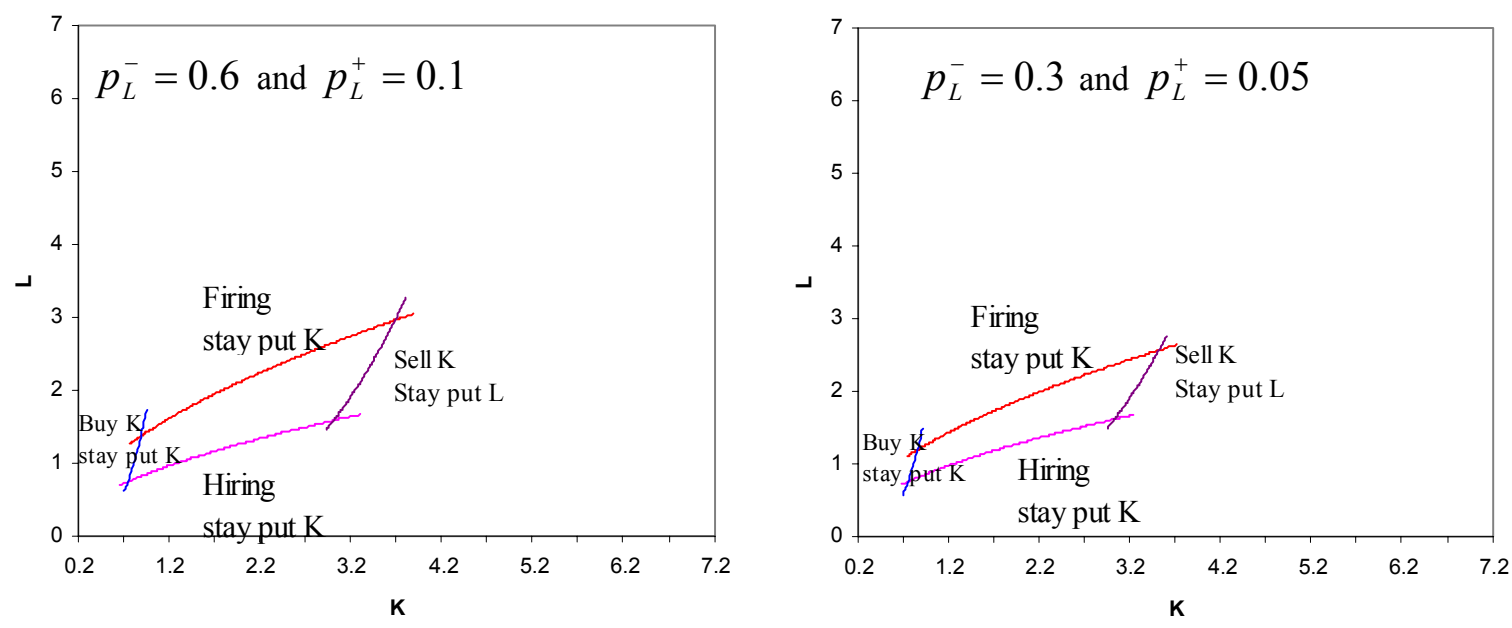

Note: The level of $Z$ is set to 1 in the numerical exercise.

Figure 2 replicates the same graphs for $\psi=1.6$, i.e. for a less competitive product market environment. Different policies are usually aimed at influencing outcomes in the markets to which they apply directly. Judging from Figure 1 and Figure 2, however, it is clear that heavier-handed product market regulation leads to significant cross-market interactions. ${ }^{20}$ The comparison indicates how different degrees of product market regulation change the likelihood of future adjustments of capital and labour. A less competitive environment (higher $\psi$ ) discourages the hiring of new workers, but by the same token the firm will retain less workers in a recession. The overall impact is a noticeable decrease in the width of the no action quadrangle. The implication is that the degree of regulation can have important ramifications for employment dynamics. The resulting employment impact of changing $\psi$ is further illustrated in the corresponding labour demand functions in Figure 3 for two alternative demand shocks $Z(Z=1$ versus $Z=2)$. Heavier product market regulation decreases the competitive pressures among firms, which increases the markup. Thus for given wages $w=\bar{w}$ and service expenses $x=\bar{x}$, factor demand decreases at the firm level. Even if the number of firms remains constant, this leads to lower employment because aggregate labour demand decreases. ${ }^{21}$ Similar graphs can be plotted for capital.

\footnotetext{
${ }^{20}$ Therefore, accounting for cross-market effects appears to be an important element of good policy design. This leads to the "all or nothing" warning issued by Coe and Snower (1997) and Orszag and Snower (1998). They argue that piecemeal labour market reforms may have had so little success because they disregarded the complementarities between a broad range of policies and institutions.

${ }^{21}$ The discontinuous four-threshold microeconomic model is likely to result in smooth macroeconomic factor demand adjustment because of time aggregation and nonsynchronous adjustment by heterogeneous agents. The numerical results are consistent with the econometric estimates in OECD (2005) suggesting that cutting barriers to product market competition to "best practice" levels would increase GDP per head by $2.0-3.5$ percent in the EU.
} 
Figure 3: Labour Demand Functions for $\psi=1.5$ versus $\psi=1.6$
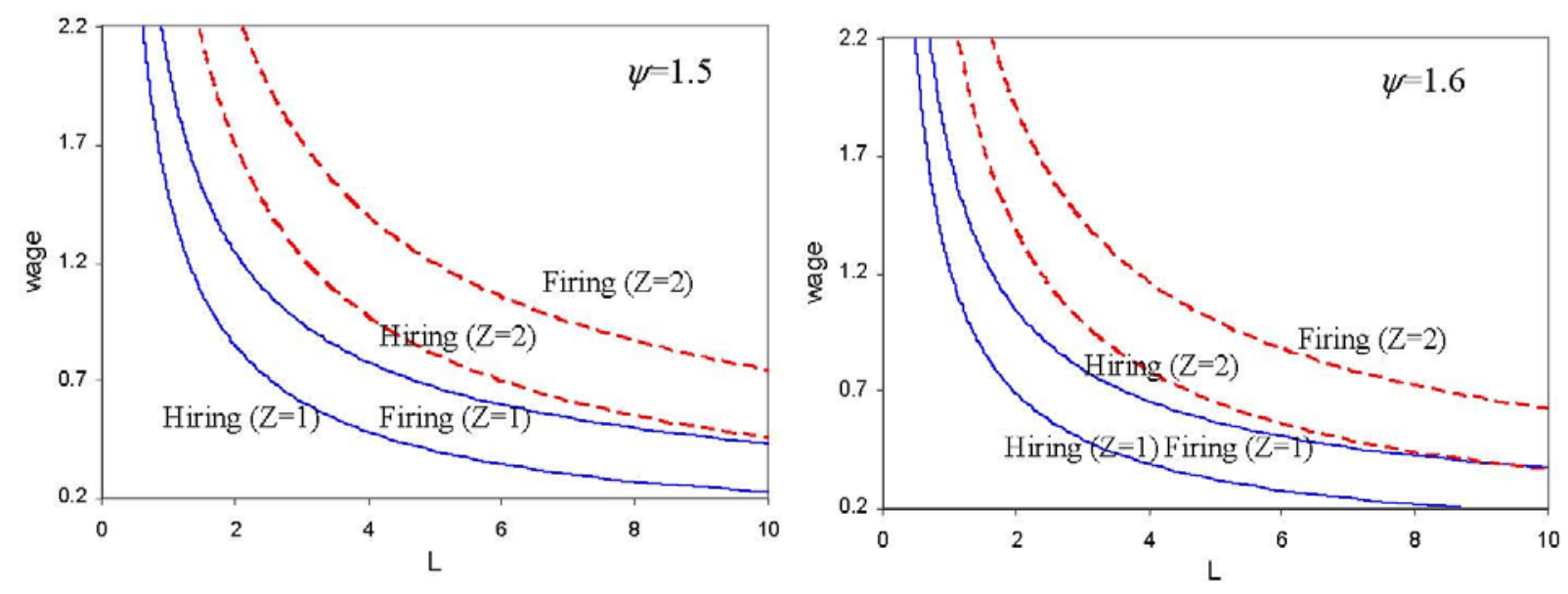

Admittedly, our analysis has been conducted in a highly simplified framework. Since lower barriers to product market competition may foster wage determination, we now consider endogenous wages. In the previous analysis we have abstracted from wage effects although it is well-known that unions are strong in regulated industries and therefore anticompetitive barriers to competition are likely to influence the outcome of the wage bargaining because firms can bear the cost of higher wages more easily and still break even. ${ }^{22}$ Ceteris paribus this will induce firms to choose capital-labour ratios higher than in a competitive situation. ${ }^{23}$ On the other hand, heightened product market competition tends to dissipate rents deriving from market power, thereby curbing wage premia. In order to throw further light on the issue of wage endogeneity, we assume that wages are determined according to

$$
w=0.85+0.3(\psi-1)
$$

Broadly speaking, tighter product market regulation (higher $\psi$ ) leads to higher wages. The implications of equation (35) are illustrated in Figure 4. The left panel of Figure 4 is identical to the left panel of Figure 1, while the right panel of Figure 4 gives the quadrangle (no action area) for $\psi=1.6$ and therefore has to be compared with the left panel of Figure 2. As expected, the calibration results indicate that the negative factor demand effects of higher barriers to competition are amplified by the endogenous wage increase. ${ }^{24}$

\section{Figure 4: The Two-Dimensional Quadrangle for $\psi=1.5$ versus $\psi=1.6$, and Endogenous Wages $w=0.85+0.3(\psi-1)$}

\footnotetext{
${ }^{22}$ There is considerable empirical literature devoted to the study of labour rent-sharing in regulated industries. See Jean and Nicoletti (2002) for an empirical investigation and Hendricks (1986) for a survey, with particular emphasis on studies of the effects of deregulation on wages.

${ }^{23}$ The capital-labour ratio would not be optimal from a social perspective because the opportunity cost of labour to the society is lower than the cost of labour to the firm.

${ }^{24}$ Another implication of Figure 4 is that deregulation of product markets, for example moving from $\psi=1.6$ to $\psi$ $=1.5$ should become relatively easier from a political economy perspective as it results in employment gains.
} 

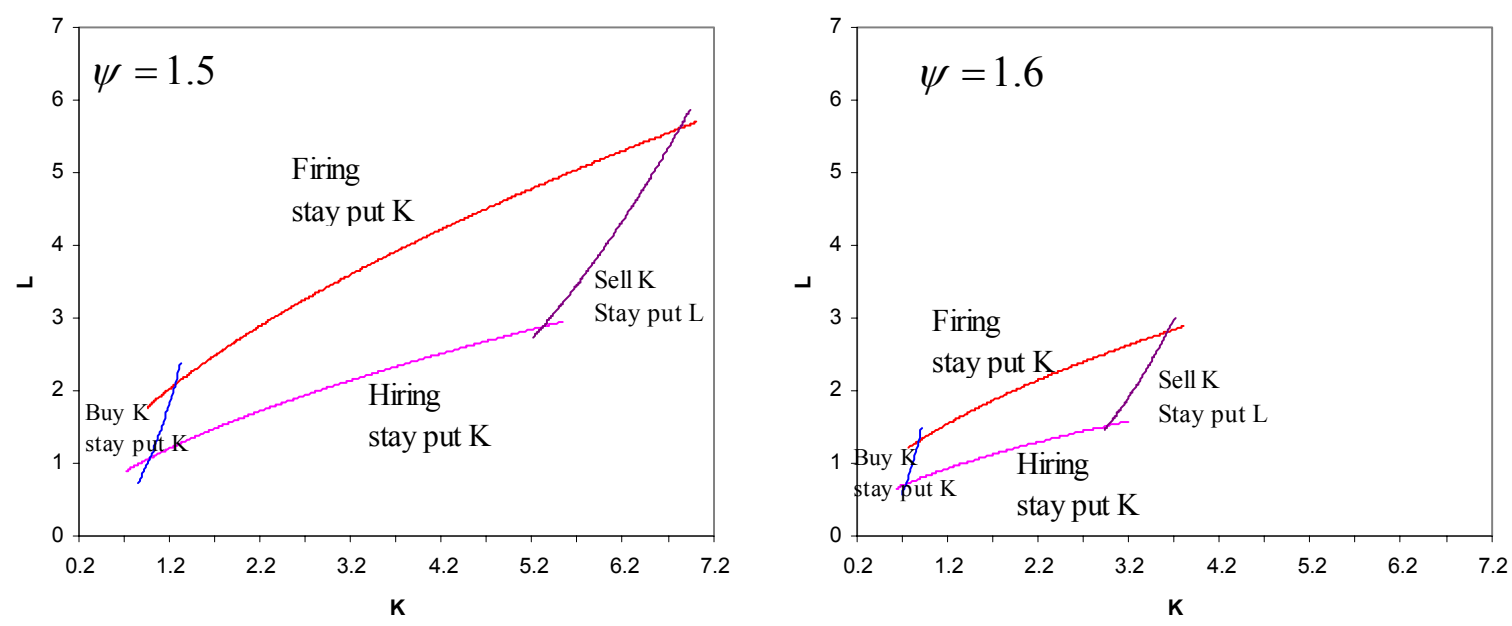

Note: $p_{L}{ }^{-}=0.6 ; p_{L}{ }^{+}=0.1$. The level of $Z$ is set to 1 in the numerical exercise.

Another relevant feature of the modelling framework is that firing costs create a hold-up problem [see, e.g. Caballero and Hammour (1998)] enabling insiders (incumbent workers) to bid up wages once they are employed. ${ }^{25}$ In other words, firing costs make it difficult for firms to fire workers, so firms hesitate to hire them in the first place, strengthening the hand of workers who already have a job Below we therefore adapt our model to an insider-outsider mechanism where firing costs increase the bargaining power of incumbent workers [see, e.g., Díaz-Vázquez, P. and D.J. Snower (2003)]. For simplicity and for clarity of exposition we assume that wages are determined as

$$
w=1-0.2\left(0.6-p_{L}^{-}\right)
$$

in this insider-outsider version of the modelling framework. Alternative barriers to competition and wage premiums are simulated in the first and second row and the first and second column of Figure 5, respectively.

\footnotetext{
${ }^{25}$ In countries with higher firing costs a large share of workers with fixed-term contracts tend to insulate insiders (permanent workers) from adjustment, thereby increasing their bargaining power.
} 
Figure 5: The Two-Dimensional Quadrangle for $\psi=1.5$ versus $\psi=1.6$ and Insider-

Outsider Wage Determination $w=1-0.2\left(0.6-p_{L}^{-}\right)$
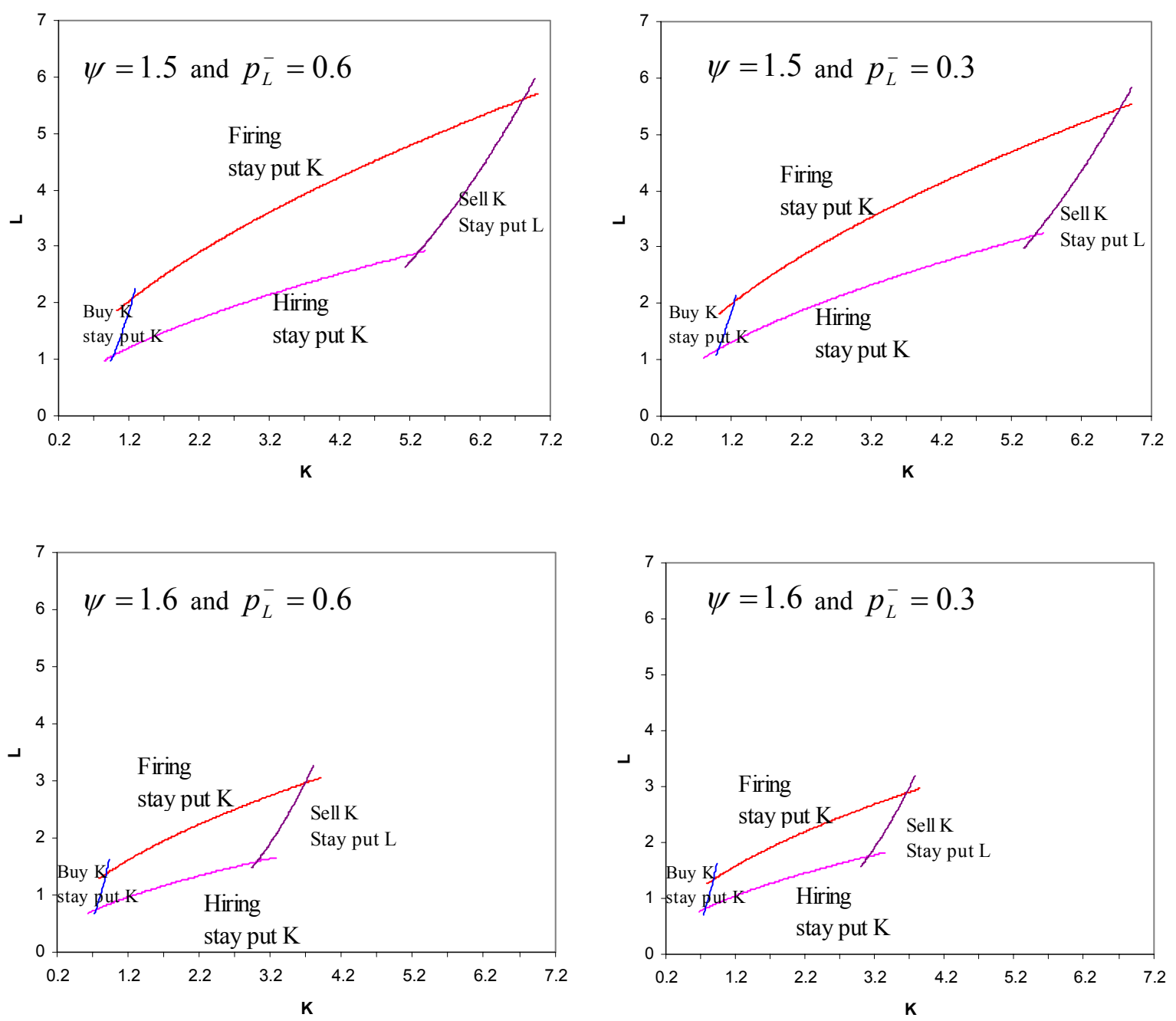

Note: The level of $Z$ is set to 1 in the numerical exercise.

The insider-outsider version of the model shows that the four-threshold area is monotonically decreasing in $\psi$ and $p_{L}^{-}$. In other words, insider-outsider considerations provide a channel which pulls the impact of firing costs via wages towards a negative impact on average employment.

Finally, cutting barriers to product market competition may also lower $p_{K}^{+}$and/or $p_{K}^{-}$and therefore entry and/or exit costs. Entry costs include all procedures that are officially required for an entrepreneur to start an industrial or commercial business. These include obtaining all necessary licenses and permits and completing any required notification, verification or registration with relevant authorities. ${ }^{26}$ Exit

\footnotetext{
${ }^{26}$ The regulation of entry and exit indices aim at capturing the actual difficulty that an entrepreneur faces to start a business, from a legal perspective as well as in practice. For further information, see Djankov et al. (2002). The "Doing Business" database of the Worldbank (see http://www.doingbusiness.org/Default.aspx) divides the process of starting and closing a company into distinct procedures, and calculates the costs and time necessary for accomplishing each procedure under normal circumstances. The OECD product market regulation database (see
} 
costs measure the time and cost involved in insolvency proceedings (for example, the average time to complete a procedure, the cost of the bankruptcy proceedings, and the recovery rate, which calculates how many cents on the dollar claimants recover from an insolvent firm). ${ }^{27}$ In Figure 6 and 7, the implications of alternative entry and exit cost regimes are illustrated graphically.

Figure 6: Capital Demand for $\psi=1.5$ versus $\psi=1.6$ and Alternative Entry and Exit Costs

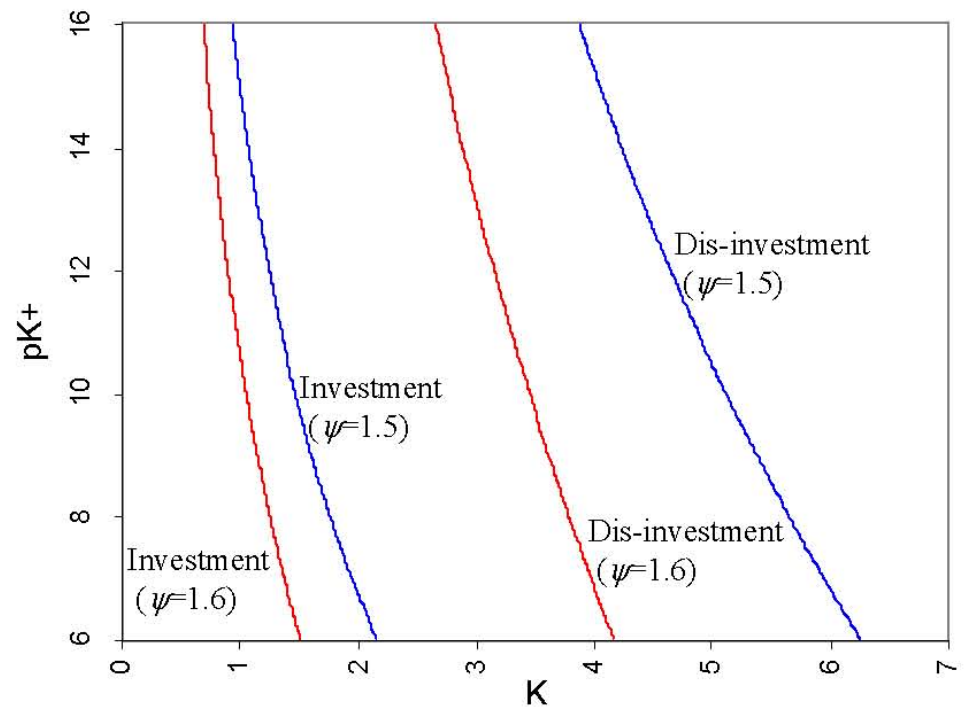

Note: The level of exit costs $\left(p_{K}{ }^{-}\right)$is always 50 percent of ${p_{K}}^{+}$.

Figure 7: Hiring and Firing Thresholds for $\psi=1.5$ versus $\psi=1.6$ and $K=2$ versus $K=2.5$
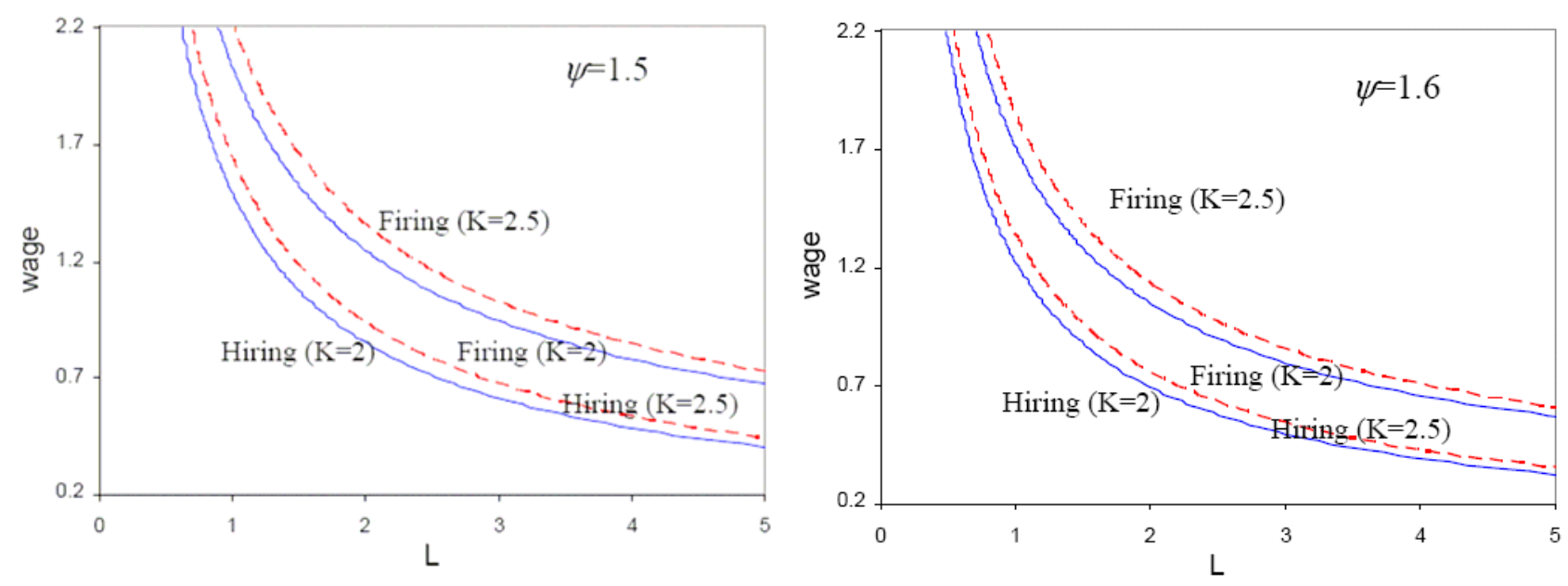

http://www.olis.oecd.org/olis/2005doc.nsf/linkto/eco-wkp(2005)6) also includes indicators of administrative barriers to entrepreneurship .

${ }^{27}$ The gulf between the Anglo-American world and Europe is striking: According to Djankov et al. (2002) establishing a firm in the US costs less than $1 \%$ of per capita GDP, while establishing a firm in continental Europe costs $18.4 \%$ of per capita GDP. In other words, the continental European entry barriers are an order of magnitude larger. 
In a model with capital and labour $F(K, L)$, firms would also adjust labour in order to maintain an optimal capital-labour ratio. The left and right panel of Figure 7 shows the hiring and firing thresholds for $K=2$ (solid lines) and $K=2.5$ (dotted lines) for $\psi=1.5$ versus $\psi=1.6$. Taking all the numerical simulations into consideration, we conclude that streamlined regulation indeed offers win-win opportunities. This confirms the mounting empirical evidence in the literature that lighter regulation can be an effective way to boost investment and employment.

\section{Concluding Remarks}

There is growing belief that the relatively poorer performance of some European countries - as compared to the U.S. - in terms of growth and employment during the last decade can be at least partially explained by the interaction of product and factor markets. This paper is an attempt at providing a unifying modelling framework that makes explicit and clarifies thinking on the interlinkages between regulation, investment and employment. ${ }^{28}$ The simulation exercises show that the intensity of product market competition variable in tandem with hiring and firing costs is an important driver of employment and growth. An important implication of our model is that product market deregulation may be very effective in terms of increasing factor demand. Another conclusion is that the impact of any one policy measure is greater if it is pushed through in tandem with other reforms than if it is implemented in isolation. ${ }^{29}$

This is by no means the last word on the causes of Europe's unemployment. But the lessons are very clear indeed. Streamlining product market regulation is likely to be beneficial for employment and growth and would therefore support the policy objectives established within the Lisbon agenda of the EU. ${ }^{30}$ The simulation results also indicate that product market reforms help to make labour market reforms more acceptable for unions. ${ }^{31}$

\footnotetext{
${ }^{28}$ Our model ignores behavioural assumptions regarding market rivalry, which in turn would necessitate some kind of game-theoretic analysis to take account of the strategic interactions among the firms, the results of which are in turn heavily dependent on assumptions regarding the information sets available and the type of game being played. The ramifications of competitive interaction on the decision making of firms have been discussed by Smit and Ankum (1993) and Leahy (1993). Leahy (1993) has shown that the assumption of myopic firms who ignore the impact of other firms' actions results in the same critical boundaries that trigger factor demand as a model in which firms correctly anticipate the strategies of other firms. Grenadier (2002) has recently extended Leahy's (1993) "Principle of Optimality of Myopic Behavior" to the apparently more complex case of dynamic oligopoly under uncertainty. Both papers therefore permit to bypass strategic general equilibrium considerations when analysing factor demand under uncertainty.

${ }^{29}$ There are important dynamic effects which are not captured by our estimates. For example, the recent empirical literature suggests a positive relationship between product market competition and innovation [see, e.g. Nickell (1996)].

${ }^{30}$ The interactions between product and factor markets may also help to understand why decelerating real wages have not translated into visibly lower unemployment in some countries in the euro area.

${ }^{31}$ Blanchard and Giavazzi (2003) have also suggested to cut barriers to product market competition first as product market deregulation should increase employment. Higher employment would buy goodwill from unions and ease implementation of additional labour market reforms.
} 
Before ending, we should note one important caveat of our approach. Our objective is limited to studying the factor demand implications of product-market regulation. It is not our purpose to evaluate the impact of regulation on social goals that could be beyond the strict sphere of employment and economic growth. Thus, our conclusions on the impact of regulation should be evaluated in a more comprehensive context before drawing welfare implications. 


\section{Appendix A: The Derivation of (21)}

Assume that the particular solution for the shadow price of capitals, $q$, has the following functional form as the particular integral components:

(A1) $q=C Z K^{\frac{\alpha}{\psi}-1} L^{\frac{1-\alpha}{\psi}}+D$,

where $C$ and $D$ are unknown constants. Then, we have

$$
\eta Z q_{Z}=\eta C Z K^{\frac{\alpha}{\psi}-1} L^{\frac{1-\alpha}{\psi}}
$$

(A3) $q_{Z Z}=0$,

(A4) $-\delta q_{K} K=-\delta\left(\frac{\alpha}{\psi}-1\right) C Z K^{\frac{\alpha}{\psi}-1} L^{\frac{1-\alpha}{\psi}}$,

$$
-\lambda q_{L} L=-\lambda \frac{1-\alpha}{\psi} C Z K^{\frac{\alpha}{\psi}-1} L^{\frac{1-\alpha}{\psi}} \text {. }
$$

Substituting the above equations into equation (19) in the text yields

$$
\left[\left(r+\delta \frac{\alpha}{\psi}+\lambda \frac{1-\alpha}{\psi}-\eta\right) C-\frac{\alpha}{\psi} a^{\frac{1}{\psi}}\right] Z K^{\frac{\alpha}{\psi}-1} L^{\frac{1-\alpha}{\psi}}+[(r+\delta) D+x]=0
$$

Equation (A6) must hold for any value of $K$ and $L$ so that bracketed terms must equal zero. We then have

$$
C=\frac{\frac{\alpha}{\psi} a^{\frac{1}{\psi}}}{r+\left(\frac{\alpha}{\psi}\right) \delta+\left(\frac{1-\alpha}{\psi}\right) \lambda-\eta} \text { and } D=-\frac{x}{r+\delta}
$$

which give equation (21) in the text:

$$
q^{P}=\frac{\frac{\alpha}{\psi} a^{\frac{1}{\psi}} Z K^{\frac{\alpha}{\psi}-1} L^{\frac{1-\alpha}{\psi}}}{r+\left(\frac{\alpha}{\psi}\right) \delta+\left(\frac{1-\alpha}{\psi}\right) \lambda-\eta}-\frac{x}{r+\delta} .
$$

\section{Appendix B: The Derivation of (22) and (23)}

Now only focusing on the homogenous part of equation (19),

$$
(r+\delta) q=-\delta q_{K} K-\lambda q_{L} L+\eta Z q_{Z}+\frac{\sigma^{2}}{2} Z^{2} q_{Z Z}
$$

The shadow price of capitals, $q$, should have the following functional form as the particular integral components: 


$$
q=A\left(Z K^{\frac{\alpha}{\psi}-1} L^{\frac{1-\alpha}{\psi}}\right)^{\beta}
$$

where $\beta$ and $A$ are unknown constants. Then, we have,

$$
\eta Z q_{Z}=\eta \beta A\left(Z K^{\frac{\alpha}{\psi}-1} L^{\frac{1-\alpha}{\psi}}\right)^{\beta}=\eta \beta q,
$$

$$
\frac{\sigma^{2}}{2} Z^{2} q_{Z Z}=\frac{\sigma^{2}}{2} \beta(\beta-1) A\left(Z K^{\frac{\alpha}{\psi}-1} L^{\frac{1-\alpha}{\psi}}\right)^{\beta}=\frac{\sigma^{2}}{2} \beta(\beta-1) q
$$

$$
\begin{aligned}
& -\delta q_{K} K=-\delta\left(\frac{\alpha}{\psi}-1\right) \beta A\left(Z K^{\frac{\alpha}{\psi}-1} L^{\frac{1-\alpha}{\psi}}\right)^{\beta}=-\delta\left(\frac{\alpha}{\psi}-1\right) \beta q \\
& -\lambda q_{L} L=-\lambda\left(\frac{1-\alpha}{\psi}\right) \beta A\left(Z K^{\frac{\alpha}{\psi}-1} \frac{1-\alpha}{L^{\psi}}\right)^{\beta}=-\lambda\left(\frac{1-\alpha}{\psi}\right) \beta q .
\end{aligned}
$$

Substituting the above equations into equation (B1) yields

$$
\left[\frac{\sigma^{2}}{2} \beta(\beta-1)-\delta\left(\frac{\alpha}{\psi}-1\right) \beta-\lambda\left(\frac{1-\alpha}{\psi}\right) \beta+\eta \beta-(r+\delta)\right] q=0 \text {. }
$$

There, we have (23), the characteristic equation, in the text:

$$
\frac{\sigma^{2}}{2} \beta(\beta-1)-\delta\left(\frac{\alpha}{\psi}-1\right) \beta-\lambda\left(\frac{1-\alpha}{\psi}\right) \beta+\eta \beta-(r+\delta)=0 .
$$

The homogeneous solutions then become

$$
q^{G}=A_{1}\left(Z K^{\frac{\alpha}{\psi}-1} L^{\frac{1-\alpha}{\psi}}\right)^{\beta_{1}}+A_{2}\left(Z K^{\frac{\alpha}{\psi}-1} L^{\frac{1-\alpha}{\psi}}\right)^{\beta_{2}}
$$

where $\beta_{1}$ and $\beta_{2}$ are the positive and negative roots respectively of the characteristic equation (B7).

\section{Appendix C: The Derivation of (24)}

Assume that the particular solution for the shadow price of capitals, $q$, has the following functional form as the particular integral components:

(C1) $v=E Z K^{\frac{\alpha}{\psi}} L^{\frac{1-\alpha}{\psi}-1}+F$,

where $E$ and $F$ are unknown constants. Then, we have 

(C2) $\eta Z v_{Z}=\eta E Z K^{\frac{\alpha}{\psi}} L^{\frac{1-\alpha}{\psi}-1}$,
(C3) $q_{Z Z}=0$,
(C4) $-\delta q_{K} K=-\delta\left(\frac{\alpha}{\psi}\right) E Z K^{\frac{\alpha}{\psi}} L^{\frac{1-\alpha}{\psi}-1}$,
(C5) $-\lambda q_{L} L=-\lambda\left(\frac{1-\alpha}{\psi}-1\right) E Z K^{\frac{\alpha}{\psi}} L^{\frac{1-\alpha}{\psi}-1}$.

Substituting the above equations into equation (19) in the text yields

$$
\left[\left(r+\delta \frac{\alpha}{\psi}+\lambda \frac{1-\alpha}{\psi}-\eta\right) E-\frac{(1-\alpha)}{\psi} a^{\frac{1}{\psi}}\right] Z K^{\frac{\alpha}{\psi}} L^{\frac{1-\alpha}{\psi}-1}+[(r+\lambda) F+w]=0
$$

Equation (C6) must hold for any value of $K$ and $L$ so that bracketed terms must equal zero. We then have

$$
E=\frac{\frac{(1-\alpha)}{\psi} a^{\frac{1}{\psi}}}{r+\left(\frac{\alpha}{\psi}\right) \delta+\left(\frac{1-\alpha}{\psi}\right) \lambda-\eta} \text { and } F=-\frac{w}{r+\lambda},
$$

which give equation (21) in the text:

$$
v^{P}=\frac{\frac{(1-\alpha)}{\psi} a^{\frac{1}{\psi}} Z K^{\frac{\alpha}{\psi}} L^{\frac{1-\alpha}{\psi}-1}}{r+\left(\frac{\alpha}{\psi}\right) \delta+\left(\frac{1-\alpha}{\psi}\right) \lambda-\eta}-\frac{w}{r+\lambda} .
$$

\section{Appendic D: The Derivation of (25) and (26):}

Now only focusing on the homogenous part of equation (20),

(D1) $\quad(r+\lambda) v=-\delta v_{K} K-\lambda v_{L} L+\eta Z v_{Z}+\frac{\sigma^{2}}{2} v^{2} V_{Z Z}$

The shadow price of employees, $v$, should have the following functional form as the particular integral components:

(D2) $\quad v=A\left(Z K^{\frac{\alpha}{\psi}} L^{\frac{1-\alpha}{\psi}-1}\right)^{\beta}$,

where $\beta$ and $A$ are unknown constants. Then, we have, 
(D3) $\eta Z v_{Z}=\eta \beta A\left(Z K^{\frac{\alpha}{\psi}} L^{\frac{1-\alpha}{\psi}-1}\right)^{\beta}=\eta \beta v$,

(D4) $\frac{\sigma^{2}}{2} Z^{2} v_{Z Z}=\frac{\sigma^{2}}{2} \beta(\beta-1) A\left(Z K^{\frac{\alpha}{\psi}} L^{\frac{1-\alpha}{\psi}-1}\right)^{\beta}=\frac{\sigma^{2}}{2} \beta(\beta-1) v$,

(D5) $\quad-\delta v_{K} K=-\delta\left(\frac{\alpha}{\psi}\right) \beta A\left(Z K^{\frac{\alpha}{\psi}} \frac{1-\alpha}{L^{\frac{1-\alpha}{\psi}}}\right)^{\beta}=-\delta\left(\frac{\alpha}{\psi}\right) \beta v$,

(D6) $-\lambda v_{L} L=-\lambda\left(\frac{1-\alpha}{\psi}-1\right) \beta A\left(Z K^{\frac{\alpha}{\psi}} L^{\frac{1-\alpha}{\psi}-1}\right)^{\beta}=-\lambda\left(\frac{1-\alpha}{\psi}-1\right) \beta v$.

Substituting the above equations into equation (D1) yields

(D7) $\left[\frac{\sigma^{2}}{2} \beta(\beta-1)-\delta\left(\frac{\alpha}{\psi}\right) \beta-\lambda\left(\frac{1-\alpha}{\psi}-1\right) \beta+\eta \beta-(r+\delta)\right] v=0$.

There, we have (23), the characteristic equation, in the text:

(D8) $\quad \frac{\sigma^{2}}{2} \beta(\beta-1)-\delta\left(\frac{\alpha}{\psi}-1\right) \beta-\lambda\left(\frac{1-\alpha}{\psi}\right) \beta+\eta \beta-(r+\delta)=0$.

The homogeneous solutions then become

(D9) $\quad v^{G}=A_{3}\left(Z K^{\frac{\alpha}{\psi}} L^{\frac{1-\alpha}{\psi}-1}\right)^{\beta_{3}}+A_{4}\left(Z K^{\frac{\alpha}{\psi}} \frac{1-\alpha}{L^{\frac{1}{\psi}}-1}\right)^{\beta_{4}}$,

where $\beta_{3}$ and $\beta_{4}$ are the positive and negative roots respectively of the characteristic equation (D7). 


\section{References:}

Abel, A.B., Dixit, A.K., Eberly, J.C. and R.S. Pindyck (1996) "Options, the Value of Capital, and Investment", Quarterly Journal of Economics 111, 753-777.

Abel, A.B. and J.C. Eberly (1994) "A Unified Model of Investment Under Uncertainty", American Economic Review 84, 1369-1384.

Acemoglu, D., Aghion, P. and Zilibotti, F. (2002). Distance to Frontier, Selection, and Economic Growth. NBER Working Paper No. 9066, Cambridge (Mass.).

Alesina, A., Ardagna, S., Nicoletti, G. and F. Schiantarelli (2005) "Regulation and Investment", Journal of the European Economic Association 3, 791-825.

Amran, M. and N. Kulatilaka (1999) Real Options: Managing Strategic Investment in an Uncertain World, Boston (Harvard Business School Press).

Angrist, J. and A. Kugler (2003) "Protective or Counterproductive? Labor Market Institutions and the Effect of Immigration on EU Natives", Economic Journal 113, F302-F331.

Bayoumi, T., Laxton, D. and Pesenti, P. (2004) "Benefits and Spillovers of Greater Competition in Europe: A Macroeconomic Assessment", Federal Reserve Bank of New York Staff Report No. 182, New York.

Bentolila, S. and Bertola, G. (1990). Firing Costs and Labor Demand: How Bad is Eurosclerosis? Review of Economic Studies 57, 381-402.

Bertola, G. and R.J. Caballero (1994) "Irreversibility and Aggregate Investment", Review of Economic Studies 61, 223-246.

Blanchard, O. and J. Tirole (2004) "Redesigning the Employment Protection System", De Economist 152, 1-20.

Boeri, T., Nicoletti, G. and S. Scarpetta (2000) "Regulation and Labor Market Performance", CEPR Discussion Paper No. 2420, London.

Bovenberg, A.L., J.J. Graafland and R.A. de Mooij (1998) Tax Reform and the Dutch Labor Market: An Applied General Equlibrium Approach, CPB Netherlands Bureau for Economic Policy Analysis, Research Memorandum 143, The Hague.

Bowman, E.H. and Moskowitz, G.T. (2001) "Real Options Analysis and Strategic Decision Making", Organization Science 12, 772-777.

Brekke, K.A. and B. ØKsendal (1994) "Optimal Switching in an Economic Activity Under Uncertainty", SIAM Journal of Control and Optimization 32, 1021-1036.

Caballero, R.J. and M.L. Hammour (1996) "On the Timing and Efficiency of Creative Destruction", Quarterly Journal of Economics 111, 805-852.

Caballero, R.J. and M.L. Hammour (1998) “The Macroeconomics of Specificity”, Journal of Political Economy 106, 724-767.

Caballero, R.J., Cowan, K.N. and E.M. Engel (2004) "Effective Labour Regulation and Microeconomic Flexibility", NBER Working Paper No. 10744, Cambridge (Mass.). 
Chen, Y.-F. and Funke, M. (2004) „Working Time and Employment Under Uncertainty“, Studies in Nonlinear Dynamics and Econometrics 8, Issue 3, Article 5, (www.bepress.com/snde/vol8/iss3/art5).

Coe, D. and D. Snower (1997) "Policy Complementarities: The Case for Fundamental Labour Market Reform", IMF Staff Papers 44, 1-35.

Copeland, T. and V. Antikarov (2001), Real Options - A Practitioner's Guide, Texere Publishing, London.

Coy, R. (1999), 'Exploiting Uncertainty: The Real-Options Revolution in Decision Making', Business Week, June 7, 118-124.

Cukierman, A. (1980) "The Effects of Uncertainty on Investment Under Risk-Neutrality With Endogenous Information", Journal of Political Economy 88, 462-475.

Demers, M. (1991) "Investment Under Uncertainty: Irreversibility and the Arrival of Information Over Time", Review of Economic Studies 58, 333-350.

Díaz-Vázquez, P. and D.J. Snower (2003) "Can Insider Power Affect Employment”, German Economic Review 4, 139-150.

Dixit, A. and R. Pindyck (1994) Investment Under Uncertainty, Princeton (Princeton University Press).

Djankov, S., La Porta, R., Lopez-de-Silanes, F. Shleifer, A. (2002) "The Regulation of Entry", Quarterly Journal of Economics 117, 1-37.

Eberly J.C. and J.A. van Mieghem (1997) "Multi-Factor Dynamic Investment under Uncertainty", Journal of Economic Theory 75, 345-387.

Grenadier, S.R. (2002). Option Exercise Games: An Application to the Equilibrium Investment Strategies of Firms. Review of Financial Studies 15, 691-721.

Hamermesh, D.S. (1993) Labor Demand, Princeton (Princeton University Press).

Hayri, A. and M. Dutz (1999) "Does More Intense Competition Lead to Higher Growth", CEPR Discussion Paper No. 2249, London.

Hendricks, W. (1986) "Collective Bargaining in Regulated Industries", Advances in Industrial and Labor Relations 3, 21-42.

IMF (2005) "Euro Area Policies: Selected Issues", IMF Country Report No. 05/266, Washington D.C.

Jean, Sébastian and Guiseppe Nicoletti (2002) "Product Market Regulation and Wage Premia in Europe and North America: An Empirical Investigation", OECD Economics Department Working Paper No. 318 , Paris.

Koedijk, K. and Kremers, J. (1996) "Market Opening, Regulation and Growth in Europe", Economic Policy 23, 445-467.

Leahy, J. (1993). Investment in Competitive Equilibrium: The Optimality of Myopic Behaviour. Quarterly Journal of Economics 108, 1105-1133.

Mortenson, D.T. and Pissarides, C.A. (1999) "New Developments in Models of Search in the Labor Market", in: Ashenfelter, O.C. and Card, D. (Eds.) Handbook of Labor Economics Vol. 3B, 2567-2627, Amsterdam (Elsevier Science). 
Nickell, S. (1996) "Competition and Company Performance", Journal of Political Economy, 104, 724746.

Nickell, S. and R. Layard (1999) "Labour Market Institutions and Economic Performance”, in: Card, D. and Ashenfelter, O. (eds.) Handbook of Labor Economics Vol 3C, 3029-3084.

Nickell, S., Nunziata, L. and W. Ochel (2005) "Unemployment in the OECD Since the 1960s: What Do We Know?", The Economic Journal 115, 1-27.

OECD (2005) "The Benefits of Liberalising Product Markets and Reducing Barriers to International Trade and Investment: The Case of the United States and the European Union", Economics Department Working Paper No. 432, Paris.

Orszag, M. and Snower, D.J. (1998). Anatomy of Policy Complementarities. Swedish Economic Policy Review 5, 303-343.

Pfann, G.A. and B. Verspagen (1989) "The Structure of Adjustment Costs for Labour in Dutch Manufacturing", Economics Letters 29, 365-371.

Press, W.H., Teukolsky, S.A., Vetterling, W.T. and B.P. Flannery (2002) Numerical Recipes in $C^{++}$: The Art of Scientific Computing, $2^{\text {nd }}$ edition, Cambridge (Cambridge University Press).

Ramey, V.A. and M.S. Shapiro (2001) "Displaced Capital: A Study of Aerospace Plant Closings", Journal of Political Economy 109, 958-992.

Smit, H. and L. Ankum (1993) "A Real Options and Game-Theoretic Approach to Corporate Investment Strategy under Competition", Financial Management 22, 241-250. 


\title{
CESifo Working Paper Series
}

\author{
(for full list see www.cesifo-group.de)
}

1501 Heikki Oksanen, Actuarial Neutrality across Generations Applied to Public Pensions under Population Ageing: Effects on Government Finances and National Saving, July 2005

1502 Xenia Matschke, Costly Revenue-Raising and the Case for Favoring Import-Competing Industries, July 2005

1503 Horst Raff and Nicolas Schmitt, Why Parallel Trade may Raise Producers Profits, July 2005

1504 Alberto Bisin and Piero Gottardi, Efficient Competitive Equilibria with Adverse Selection, July 2005

1505 Peter A. Zadrozny, Necessary and Sufficient Restrictions for Existence of a Unique Fourth Moment of a Univariate GARCH(p,q) Process, July 2005

1506 Rainer Niemann and Corinna Treisch, Group Taxation, Asymmetric Taxation and Cross-Border Investment Incentives in Austria, July 2005

1507 Thomas Christiaans, Thomas Eichner and Ruediger Pethig, Optimal Pest Control in Agriculture, July 2005

1508 Biswa N. Bhattacharyay and Prabir De, Promotion of Trade and Investments between China and India: The Case of Southwest China and East and Northeast India, July 2005

1509 Jean Hindriks and Ben Lockwood, Decentralization and Electoral Accountability: Incentives, Separation, and Voter Welfare, July 2005

1510 Michelle R. Garfinkel, Stergios Skaperdas and Constantinos Syropoulos, Globalization and Domestic Conflict, July 2005

1511 Jesús Crespo-Cuaresma, Balázs Égert and Ronald MacDonald, Non-Linear Exchange Rate Dynamics in Target Zones: A Bumpy Road towards a Honeymoon - Some Evidence from the ERM, ERM2 and Selected New EU Member States, July 2005

1512 David S. Evans and Michael Salinger, Curing Sinus Headaches and Tying Law: An Empirical Analysis of Bundling Decongestants and Pain Relievers, August 2005

1513 Christian Keuschnigg and Martin D. Dietz, A Growth Oriented Dual Income Tax, July 2005

1514 Fahad Khalil, David Martimort and Bruno Parigi, Monitoring a Common Agent: Implications for Financial Contracting, August 2005 
1515 Volker Grossmann and Panu Poutvaara, Pareto-Improving Bequest Taxation, August 2005

1516 Lars P. Feld and Emmanuelle Reulier, Strategic Tax Competition in Switzerland: Evidence from a Panel of the Swiss Cantons, August 2005

1517 Kira Boerner and Silke Uebelmesser, Migration and the Welfare State: The Economic Power of the Non-Voter?, August 2005

1518 Gabriela Schütz, Heinrich W. Ursprung and Ludger Wößmann, Education Policy and Equality of Opportunity, August 2005

1519 David S. Evans and Michael A. Salinger, Curing Sinus Headaches and Tying Law: An Empirical Analysis of Bundling Decongestants and Pain Relievers, August 2005

1520 Michel Beine, Paul De Grauwe and Marianna Grimaldi, The Impact of FX Central Bank Intervention in a Noise Trading Framework, August 2005

1521 Volker Meier and Matthias Wrede, Pension, Fertility, and Education, August 2005

1522 Saku Aura and Thomas Davidoff, Optimal Commodity Taxation when Land and Structures must be Taxed at the Same Rate, August 2005

1523 Andreas Haufler and Søren Bo Nielsen, Merger Policy to Promote 'Global Players’? A Simple Model, August 2005

1524 Frederick van der Ploeg, The Making of Cultural Policy: A European Perspective, August 2005

1525 Alexander Kemnitz, Can Immigrant Employment Alleviate the Demographic Burden? The Role of Union Centralization, August 2005

1526 Baoline Chen and Peter A. Zadrozny, Estimated U.S. Manufacturing Production Capital and Technology Based on an Estimated Dynamic Economic Model, August 2005

1527 Marcel Gérard, Multijurisdictional Firms and Governments' Strategies under Alternative Tax Designs, August 2005

1528 Joerg Breitscheidel and Hans Gersbach, Self-Financing Environmental Mechanisms, August 2005

1529 Giorgio Fazio, Ronald MacDonald and Jacques Mélitz, Trade Costs, Trade Balances and Current Accounts: An Application of Gravity to Multilateral Trade, August 2005

1530 Thomas Christiaans, Thomas Eichner and Ruediger Pethig, A Micro-Level 'Consumer Approach' to Species Population Dynamics, August 2005

1531 Samuel Hanson, M. Hashem Pesaran and Til Schuermann, Firm Heterogeneity and Credit Risk Diversification, August 2005 
1532 Mark Mink and Jakob de Haan, Has the Stability and Growth Pact Impeded Political Budget Cycles in the European Union?, September 2005

1533 Roberta Colavecchio, Declan Curran and Michael Funke, Drifting Together or Falling Apart? The Empirics of Regional Economic Growth in Post-Unification Germany, September 2005

1534 Kai A. Konrad and Stergios Skaperdas, Succession Rules and Leadership Rents, September 2005

1535 Robert Dur and Amihai Glazer, The Desire for Impact, September 2005

1536 Wolfgang Buchholz and Wolfgang Peters, Justifying the Lindahl Solution as an Outcome of Fair Cooperation, September 2005

1537 Pieter A. Gautier, Coen N. Teulings and Aico van Vuuren, On-the-Job Search and Sorting, September 2005

1538 Leif Danziger, Output Effects of Inflation with Fixed Price- and Quantity-Adjustment Costs, September 2005

1539 Gerhard Glomm, Juergen Jung, Changmin Lee and Chung Tran, Public Pensions and Capital Accumulation: The Case of Brazil, September 2005

1540 Yvonne Adema, Lex Meijdam and Harrie A. A. Verbon, The International Spillover Effects of Pension Reform, September 2005

1541 Richard Disney, Household Saving Rates and the Design of Social Security Programmes: Evidence from a Country Panel, September 2005

1542 David Dorn and Alfonso Sousa-Poza, Early Retirement: Free Choice or Forced Decision?, September 2005

1543 Clara Graziano and Annalisa Luporini, Ownership Concentration, Monitoring and Optimal Board Structure, September 2005

1544 Panu Poutvaara, Social Security Incentives, Human Capital Investment and Mobility of Labor, September 2005

1545 Kjell Erik Lommerud, Frode Meland and Odd Rune Straume, Can Deunionization Lead to International Outsourcing?, September 2005

1546 Robert Inklaar, Richard Jong-A-Pin and Jakob de Haan, Trade and Business Cycle Synchronization in OECD Countries: A Re-examination, September 2005

1547 Randall K. Filer and Marjorie Honig, Endogenous Pensions and Retirement Behavior, September 2005

1548 M. Hashem Pesaran, Til Schuermann and Bjoern-Jakob Treutler, Global Business Cycles and Credit Risk, September 2005 
1549 Ruediger Pethig, Nonlinear Production, Abatement, Pollution and Materials Balance Reconsidered, September 2005

1550 Antonis Adam and Thomas Moutos, Turkish Delight for Some, Cold Turkey for Others?: The Effects of the EU-Turkey Customs Union, September 2005

1551 Peter Birch Sørensen, Dual Income Taxation: Why and how?, September 2005

1552 Kurt R. Brekke, Robert Nuscheler and Odd Rune Straume, Gatekeeping in Health Care, September 2005

1553 Maarten Bosker, Steven Brakman, Harry Garretsen and Marc Schramm, Looking for Multiple Equilibria when Geography Matters: German City Growth and the WWII Shock, September 2005

1554 Paul W. J. de Bijl, Structural Separation and Access in Telecommunications Markets, September 2005

1555 Ueli Grob and Stefan C. Wolter, Demographic Change and Public Education Spending: A Conflict between Young and Old?, October 2005

1556 Alberto Alesina and Guido Tabellini, Why is Fiscal Policy often Procyclical?, October 2005

1557 Piotr Wdowinski, Financial Markets and Economic Growth in Poland: Simulations with an Econometric Model, October 2005

1558 Peter Egger, Mario Larch, Michael Pfaffermayr and Janette Walde, Small Sample Properties of Maximum Likelihood Versus Generalized Method of Moments Based Tests for Spatially Autocorrelated Errors, October 2005

1559 Marie-Laure Breuillé and Robert J. Gary-Bobo, Sharing Budgetary Austerity under Free Mobility and Asymmetric Information: An Optimal Regulation Approach to Fiscal Federalism, October 2005

1560 Robert Dur and Amihai Glazer, Subsidizing Enjoyable Education, October 2005

1561 Carlo Altavilla and Paul De Grauwe, Non-Linearities in the Relation between the Exchange Rate and its Fundamentals, October 2005

1562 Josef Falkinger and Volker Grossmann, Distribution of Natural Resources, Entrepreneurship, and Economic Development: Growth Dynamics with Two Elites, October 2005

$1563 \mathrm{Yu}-\mathrm{Fu}$ Chen and Michael Funke, Product Market Competition, Investment and Employment-Abundant versus Job-Poor Growth: A Real Options Perspective, October 2005 